\title{
Investigating the host specificity of Campylobacter jejuni and Campylobacter coli by sequencing gyrase subunit $A$
}

\author{
Catherine Ragimbeau ${ }^{1 *}$, Stephanie Colin ${ }^{2}$, Anthony Devaux ${ }^{1}$, Frédéric Decruyenaere ${ }^{3}$, Henry-Michel Cauchie ${ }^{4}$, \\ Serge Losch ${ }^{5}$, Christian Penny ${ }^{4}$ and Joël Mossong ${ }^{1}$
}

\begin{abstract}
Background: Surveillance and field investigations of Campylobacter infections require molecular tools with genetic markers appropriate for tracing purposes, i.e. based on the principle that some Campylobacter lineages acquire a host signature under adaptive selection pressure. We developed a sequence-based method targeting the quinolone resistance determining region within the subunit A of DNA gyrase (gyrA). Host specificity was evaluated by characterizing two collections of Campylobacter jejuni $(\mathrm{N}=430)$ and Campylobacter coli $(\mathrm{N}=302)$ originating from surface waters, domestic mammals and poultry.

Results: Based on nucleotide identity, a total of 80 gyrA alleles were observed. Thirty nine alleles assigned to C. coli encoding two peptides fell into three clades: two associated with surface waters and one associated with domestic mammals and poultry. The variability in GC content generated by synonymous mutations suggested that surface waters isolates originated from two distinct ecological niches. A total of 42 alleles were recorded from C. jejuni strains and encoded 8 peptides including one lying in a distinct lineage associated with wildlife. Seven of the 23 alleles encoding peptide \#1 displayed the synonymous mutation G408A not identified in poultry isolates. By contrast, the substitution Ser22Gly observed in 4 different peptide groups was significantly associated with domestic birds ( $P=0.001)$. The change in amino acid sequences Thr86lle conferring resistance to quinolones was significantly associated with poultry $(P<0.001)$ in both $C$. jejuni and C. coli with $38.7 \%$ and $67.9 \%$ of quinolone-resistant strains, respectively.

Conclusions: The gyrA typing method presented here is an informative tool as sequences appear to be predictive of particular ecological niches. Combined with multi-locus sequence typing, it could increase the resolution of source attribution, and combined with porA/flaA typing it could be suitable for detecting temporal clusters of human cases. All gyrA alleles identified were deposited in the freely accessible online database http://pubmlst.org/campylobacter.
\end{abstract}

Keywords: Campylobacter jejuni, Campylobacter coli, Gyrase, Typing, MLST, GyrA, Surveillance, Surface water

\section{Background}

According to the EU Summary Report 2013, Campylobacter infections have superseded Salmonella infections in many Member States as the most frequently reported foodborne infection, and many countries have been witnessing recent increases in reported cases [1]. In 2011, the incidence rate in Luxembourg has increased to 138 per 100,000 population, which is a national record and among the highest in Europe [1]. As a result, the competent

\footnotetext{
* Correspondence: catherine.ragimbeau@Ins.etat.lu

${ }^{1}$ National Health Laboratory, Surveillance and Epidemiology of Infectious Diseases, 1 rue Louis Rech, Dudelange L-3555, Luxembourg

Full list of author information is available at the end of the article
}

national authorities in Luxembourg have recognized the rising trend of Campylobacter infections as a national public health priority [2]. Approximately 80 to $90 \%$ of the human cases is caused by the species $C$. jejuni and the remainder is primarily caused by C. coli. While exposure to contaminated food (and in particular chicken) is thought to be the most important route of transmission of campylobacteriosis, several studies in Europe have indicated that environmental routes of transmission could be important [3-5].

As a complimentary approach to classical epidemiology (e.g. measuring food intake and other exposures), molecular epidemiology has proved very useful for investigating 
likely sources of Campylobacter infections [6-9]. However, predicting the biological host from the genotype is challenging because Campylobacter species display a weak clonal population structure, in which the different lineages and the relatedness between isolates cannot be easily determined. The multilocus sequence typing (MLST) method exploits the relative conservation in sequence of 7 core genes encoding housekeeping functions in which variations are more likely to be selectively neutral [10]. This approach is now recognized as the gold standard typing method for this bacteria genus but for short-term epidemiology like cluster detection or for tracing transmission routes in a defined space-time window, MLST should be combined with other markers to increase the discrimination power of the typing scheme. For that purpose, the loci encoding the flagellin flaA, $f l a B$ and the variable outer membrane protein por $A$ were proposed [8].

In addition to these genotypic aspects, a phenotypic trait related to fluoroquinolone resistance has become of major epidemiologic relevance. Indeed, about half of $C$. jejuni isolated from humans in Europe are resistant to ciprofloxacin, an antimicrobial often used for treating severe foodborne infections. Since Campylobacter is a zoonotic bacterium, the emergence of resistant strains has been linked to a selective pressure generated by the extensive use of quinolones in food-producing animals [11]. Enrofloxacin is one of the major fluoroquinolone agents for prophylactic or therapeutic veterinary purposes. In poultry production, the whole flock is generally treated by adding this compound to the drinking water, whereas, in cattle or pig production, treatment is often restricted to diseased animals. As a result, the highest levels of quinolone resistance are found in Campylobacter isolated from chicken (Gallus gallus) [12]. Fluoroquinolones are categorized as critically important drugs for human medicine by the WHO [13], and consequently surveillance programs to monitor trends in use [14] and resistance $[15,16,12]$ have been implemented. For Campylobacter, the principal molecular mechanisms of quinolone resistance consists in a single mutation C257T in the $\operatorname{gyr}$ A gene $[17,18]$. Consequently, PCR or sequencedbased methods targeting this quinolone resistance determining region (QRDR) have been shown to be highly predictive for detecting phenotypically resistant variants [16]. Moreover, previous work on gyrA suggested this locus might provide a host signature and thus be a good candidate for typing purposes $[19,20]$.

The aims of this study were thus to evaluate the host specificity of the gyrA gene and to monitor quinolone resistance in a large Campylobacter jejuni and coli strain collection originating from domesticated animals and surface water samples potentially contaminated by wildlife.

\section{Methods}

\section{Isolates from non-human sources}

For this study, we characterized $430 \mathrm{C}$. jejuni and $280 \mathrm{C}$. coli isolated in Luxembourg from surface waters (SW), domesticated mammals (DM) and poultry (P) between 2005 and 2012. Identification to the species level of the isolates was previously achieved by a duplex real-time PCR targeting the hip $\mathrm{O}$ gene of $C$. jejuni and a conserved region of the gyrA gene of $C$. jejuni and $C$. coli (outside the QRDR). Primer and probe combinations for the hipO Taqman-qPCR and gyrA FRET-qPCR systems were selected from published methods [21,22]. Real-time PCRs were performed using the FastStart DNA Master ${ }^{\text {plus }}$ HybProbe kit (Roche Diagnostic, Prophac, Luxembourg) in a total reaction volume of $20 \mu \mathrm{l}$ containing the following final primer and probe concentrations: hip $\mathrm{O}$ primers $0.5 \mu \mathrm{M}$, hip $\mathrm{O}$ Taqman probe $0.1 \mu \mathrm{M}$, gyrA primers $1 \mu \mathrm{M}$ and gyrA sensor and anchor probes $0.2 \mu \mathrm{M}$. The PCR programme included an initial activation step of $10 \mathrm{~min}$ at $95^{\circ} \mathrm{C}, 30$ amplification cycles of $6 \mathrm{~s}$ at $95^{\circ} \mathrm{C}, 12 \mathrm{~s}$ at $54^{\circ} \mathrm{C}$ and $25 \mathrm{~s}$ at $72^{\circ} \mathrm{C}$, followed by a melting curve analysis step of $1 \mathrm{~min}$ at $95^{\circ} \mathrm{C}, 50 \mathrm{~s}$ at $38^{\circ} \mathrm{C}$, a rise to $80^{\circ} \mathrm{C}$ with an increase rate of $0.1^{\circ} \mathrm{C} \mathrm{s}^{-1}$, and final cooling of $30 \mathrm{~s}$ at $40^{\circ} \mathrm{C}$. C. jejuni and C. coli were identified by reading both the amplification and melting curves. Isolates with an atypical profile (i.e. hipO negative and a gyrA melting curve corresponding to no known species) were further confirmed as C. jejuni with a conventional agarose gel-based PCR targeting the hipO gene with a new set of primers designed for this study: hipO-58 F 5'CAAATTCATGAAAATCCTG 3' and hipO1057R 5'TGTCGTTTTCATTTTCTAA 3'.

DM isolates were obtained from faeces while $P$ isolates were obtained from raw meat and faeces. Because only few local C. coli isolates of pig origin were available for analysis $(\mathrm{N}=23)$, we characterized as part of the $\mathrm{DM}$ collection further 22 porcine C. coli strains from collections from France $(\mathrm{N}=16$, year 2008) and Belgium $(\mathrm{N}=6$, year 2010).

A total of $31 \mathrm{SW}$ sites were sampled from different geographic areas in Luxembourg (surface $2,586 \mathrm{~km}^{2}$ ) including rivers, pond waters, recreational waters and wastewater treatment plant outlets between January 2011 and December 2012. The SW C. jejuni $(\mathrm{N}=206)$ and C. coli $(\mathrm{N}=123)$ isolates were obtained from 23 and 22 different water sites, respectively, and both species were simultaneously obtained from 14 sites.

The $C$. jejuni collection included $99 \mathrm{DM}$ isolates (bovine, $\mathrm{N}=81 ; \operatorname{dog}, \mathrm{N}=6$; ovine, $\mathrm{N}=4$; equidae, $\mathrm{N}=4$; goat, $\mathrm{N}=3$; cat, $\mathrm{N}=1$ ) and $125 \mathrm{P}$ isolates (broiler, $\mathrm{N}=94$; turkey, $\mathrm{N}=$ 19 , duck, $\mathrm{N}=8$; quail, $\mathrm{N}=3$, ostrich, $\mathrm{N}=1$ ). The $C$. coli collection included $46 \mathrm{DM}$ isolates (pig, $\mathrm{N}=45$; goat, $\mathrm{N}=1$ ) and $133 \mathrm{P}$ isolates (broiler, $\mathrm{N}=104$; turkey, $\mathrm{N}=25$; duck, $\mathrm{N}=1$; guinea fowl, $\mathrm{N}=1$, quail, $\mathrm{N}=1$; ostrich, $\mathrm{N}=1$ ). All isolates were stored in FBP medium [23] at $-70^{\circ} \mathrm{C}$ until use. 


\section{DNA isolation}

Isolates were subcultured on chocolate PolyVitex agar (ref 42079, Biomérieux, France) at $+42^{\circ} \mathrm{C}$ for $24 \mathrm{~h}$ in a microaerobic atmosphere $\left(6 \% \mathrm{O}_{2}, 3.6 \% \mathrm{CO}_{2}, 3.6 \% \mathrm{H}_{2}\right.$ and $86.9 \% \mathrm{~N}_{2}$ ) generated by an Anoxomat ${ }^{\mathrm{Tm}}$ system (Mart Microbiology, Belgium). Bacterial DNA was extracted from these cultures with the DNA QIAamp mini Kit 250 (ref 51306, Qiagen, The Netherlands). From stock solutions, tenfold dilutions in buffer AE (10 mM Tris $\cdot \mathrm{Cl} ; 0.5 \mathrm{mM}$ EDTA; $\mathrm{pH}$ 9.0) were prepared for the PCR assays.

\section{gyrA sequencing}

The partial gene sequence of gyrA targeting the quinolone resistance determining region (QRDR) was amplified and sequenced with the forward primer GYR-for (5'-GCTGATGCAAAAGKTTAATATGC-3') and the reverse primer GYR-rev (5'-TTTGTCGCCATACCTACA GC-3') designed for this study. Amplifications were carried out in a total volume of $20 \mu \mathrm{l}$ using the AmpliTaq Gold 360 Master Mix (code 4398901, Applied Biosystems, Belgium). The primer concentration was adjusted at $0.2 \mu \mathrm{mol} \mathrm{l}^{-1}$ each in the reaction mix and the cycling conditions were as follows: $95^{\circ} \mathrm{C}$ for $10 \mathrm{~min}$ then $35 \mathrm{cy}$ cles of $95^{\circ} \mathrm{C} 30 \mathrm{~s}, 55^{\circ} \mathrm{C} 30 \mathrm{~s}, 72^{\circ} \mathrm{C} 50 \mathrm{~s}$. The reaction was completed by a final extension of $5 \mathrm{~min}$ at $72^{\circ} \mathrm{C}$. For the sequencing step, the PCR products were diluted ten-fold in water and the sequencing reaction was carried out directly with $2 \mu \mathrm{l}$ from these dilutions. The sequencing reactions were purified by the Agencourt $^{\oplus}$ CleanSEQ $^{\circ}$ method (Protocol 000411v001, Beckman Coulter, USA) and products were analyzed with an ABI Prism 3130XL sequencer (ABI, Life Technologies, Belgium).

An in-house nomenclature was determined for the assignment of the nucleotide and peptide sequences (length analyzed $=496 \mathrm{bp}$ corresponding to $165 \mathrm{aa}$ ): numbering of the alleles of $C$. coli started at \#301. All the sequences identified and assigned were included in the online database Campylobacter Multi Locus Sequence Typing [24] and sequence query was done by selecting the loci named fn_gyrA and fp_gyrA (for nucleotide alleles and peptide sequences, respectively). The number assignment of alleles was based on a larger strain collection than the one presented herein, such that not all allele numbers are represented in this study.

\section{Multi Locus Sequence Typing (MLST)}

The MLST protocol for amplification and sequencing of the seven housekeeping genes developed by Dingle et al. was used for this study [25,26]. Sequencing steps were carried out as described earlier (dilution of the PCR amplicons in water, use of magnetic beads for purification of the sequence reactions). Automated data analysis and library matching were set up with SeqScape ${ }^{\oplus}$ software v2.5
(ABI, Life Technologies, Belgium). New alleles and STs identified were submitted for assignment to the MLST database [24].

\section{Data analysis}

The START 2 program [27] was used for: (i) calculating the index of association $\left(\mathrm{I}_{\mathrm{A}}\right)$, reflecting the degree of clonality in each population (SW, DM and P), from allelic profiles generated by MLST and gyrA data combined; (ii) determining the ratio of non-synonymous $\left(d_{\mathrm{N}}\right)$ to synonymous $\left(d_{\mathrm{S}}\right)$ substitutions per nucleotide site in the $\operatorname{gyr} A$ sequence. The index of population differentiation ( $F$ statistic, denoted $F_{\mathrm{ST}}$ ) was estimated using Arlequin, v3.1 program [28] from the concatenated sequences of the 8 loci (MLST combined with $g y r A$ ). An $F_{\mathrm{ST}}$ of 0 indicates that two populations are indistinguishable, whereas an $F_{\mathrm{ST}}$ value of 1 indicates that two populations are genetically distinct. The discriminating power of the molecular methods (MLST, gyrA sequencing) were estimated by the Simpson's Index of Diversity (SID) applied to the test population and calculated with the freely available online tool Comparing Partitions [29,30]. The SID measures the probability that two individuals selected at random belong to the same genotype. Alignment of gyrA sequences and calculation of GC content (\%) was performed with BioEdit v7.0.5.3 [31]. The neighbour-joining radial tree was constructed using MEGA 5 [32] with the gyrA sequences from all the alleles identified in both species. The robustness of the nodes was evaluated by bootstrapping (200 replicates). Normal distribution verification and unpaired two-sample t-test comparisons on mean GC percentages between gyrA clusters were done using the GraphPad Prism software tool.

\section{Results}

\section{gyrA sequencing data}

With the primers designed in this study, amplification and partial sequencing of gyrA was successfully performed for all strains tested in both species $C$. jejuni and C. coli. An overall total of 80 different nucleotide alleles were identified. Alignment of the sequences revealed two main allelic groups, sharing overall $81.3 \%$ nucleotide sequence identity. A first group of 41 alleles contained all but one $C$. jejuni isolates $(99.8 \%$ of the C. jejuni collection). A second group of 39 alleles contained all but 7 C. coli isolates ( $97.7 \%$ of the $C$. coli collection). Interestingly, the 39 alleles related to $C$. coli encode only two different peptide sequences that differ in one single amino acid (Thr86lle substitution giving rise to quinolone resistance). By contrast, the 41 alleles related to $C$. jejuni encode 8 different peptide sequences (numbered between $\# 1$ and \#14). The $d_{\mathrm{N}} / d_{\mathrm{S}}$ ratios were lower for the $C$. coli $(0.0075)$ than the $C$. jejuni (0.0498) collections, reflecting a higher level of synonymous changes 
within the gyrA sequences of the C. coli than in those of C. jejuni. The phylogenic tree in Figure 1 further highlights two clades for C. jejuni and three clades for C. coli.

\section{Genetic diversity among the gyrA sequences within each species}

The nucleotide sequences were aligned to an arbitrarily chosen reference allele (allele \#1 and \#301 for C. jejuni and C. coli, respectively). A total of 36 and 46 polymorphic sites were found for C. jejuni and C. coli, respectively. Next, nucleotide alleles were classified in a two-step approach: first, according to the encoded peptide (i.e. non-synonymous mutations) and second, according to similarities in nucleotide sequences (i.e. synonymous mutations). Tables 1 and 2 display this classification and

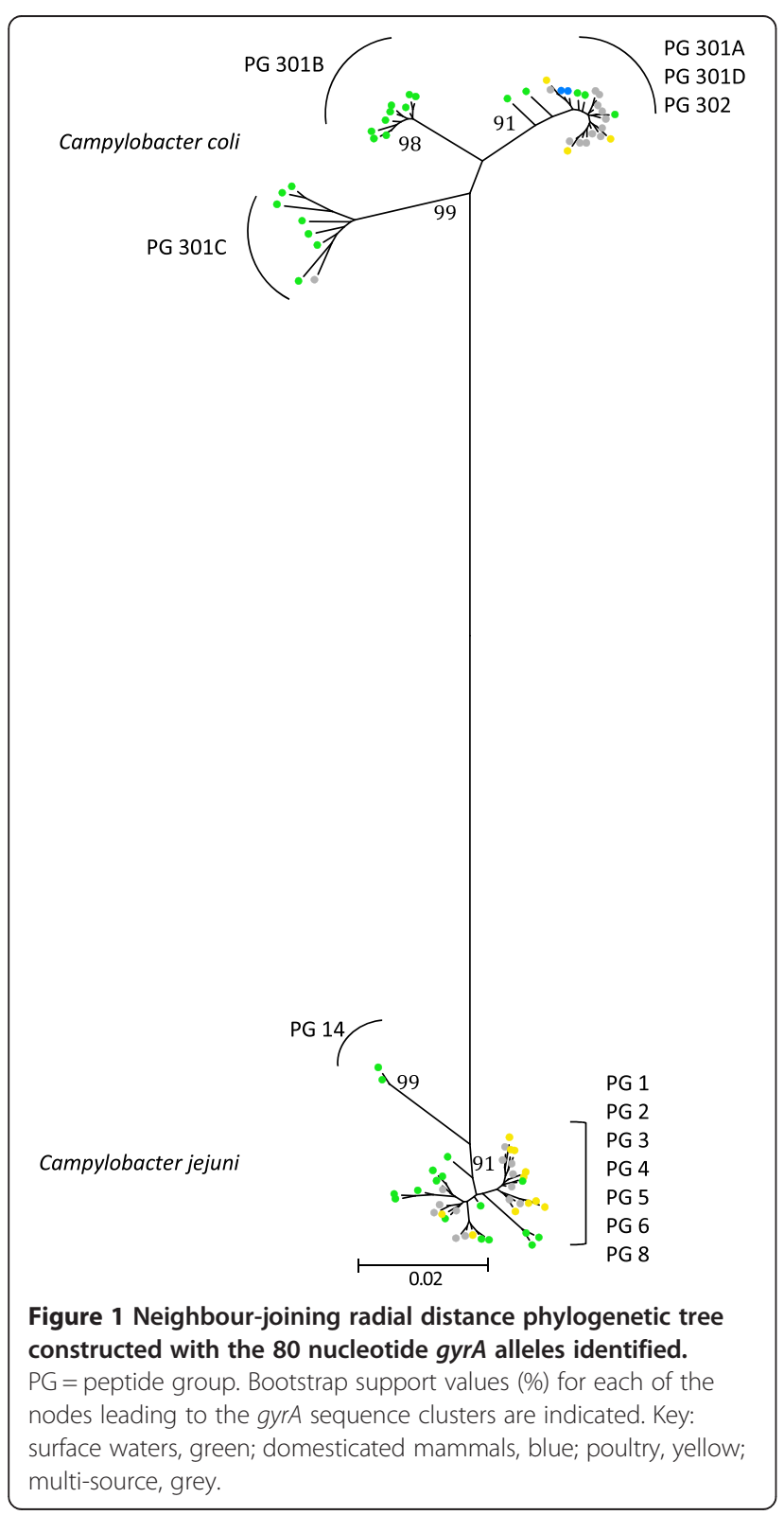

show a selection of synonymous and non-synonymous changes in sequences that were common to several alleles and which determined different peptide groups (PG). The 430 isolates of the $C$. jejuni collection were classified into 9 PGs: 8 corresponded to PGs \#1, 2, 3, 4, 5, 6, 8 and 14 related to $C$. jejuni (41 nucleotide alleles) and one corresponded to PG \#301 related to C. coli (encoded by the nucleotide allele \#301, Table 1). For refining grouping among the 302 C. coli strains, PG \#301 (originally composed of 39 nucleotide alleles) was subdivided in four parts named A, B, C and D according to similarities in synonymous mutations in their nucleotide sequences (Table 2). PG \#302 included all strains with the quinolone resistance $\mathrm{C} 257 \mathrm{~T}$ mutation (10 nucleotide alleles). The remaining peptide groups were specific to the $C$. jejuni species (PGs \#7, 8, 9 and 23).

Figure 2 shows the GC contents of the nucleotide sequences arranged by PGs. Variations in base composition can be observed. A significantly higher GC content (unpaired t-test, $\mathrm{p}<0.001$ ) was found in PG \#301C from $C$. coli (average $=37.65 \%, \mathrm{SD}=0.26$ ) compared to the other two groups PG \#301B and PG \#301D (average $=36.83 \%$, $\mathrm{SD}=0.19$ ). By contrast, alleles from the $C$. jejuni species appear more homogeneous in their base contents. The overall average was of $35.33 \%$ ( $\mathrm{SD}=0.25$ ) when excluding PG \#14, which displays the lowest level recorded in the gyrA sequences (average $=33.57 \%, \mathrm{SD}=0.14 ; \mathrm{p}<0.001$ ).

\section{Distribution of $g y r A$ alleles by source}

The collection of strains used in this study originated from three sources: surface waters (SW), domestic mammals $(\mathrm{DM})$ and poultry $(\mathrm{P})$. Regarding the $C$. jejuni collection, PG \#1 is the largest group, including 23 nucleotide alleles corresponding to more than $50 \%$ of the alleles identified for this species (Table 1). However, data could be subdivided in two main sets: (i) the alleles \#1, 4, 5 and 7 were commonly identified from the 3 sources $(\mathrm{N}=76$ for SW, $\mathrm{N}=61$ for $\mathrm{DM}$ and $\mathrm{N}=54$ for $\mathrm{P}$ ); (ii) 16 alleles were shared by 105 strains predominantly from environmental source ( $\mathrm{N}=90$ i.e. $43.7 \%$ of the $\mathrm{SW}$ collection). Within this latest set, the synonymous substitution G408A in nucleotide sequences was never identified from poultry strains. PG \#2 is encoded by alleles mainly identified from animal sources represented by $23.3 \%, 20.2 \%$ and $12.6 \%$ of the P, DM and SW collections respectively. The PGs \#3, 4, 5 and 8 share the synonymous substitution A64G in their nucleotide alleles, significantly associated with poultry source (unpaired t-test, $P<0.001$ ). Finally, the only strain harboring an allele specific of the $C$. coli species was isolated from poultry.

The distribution of the C. coli strains within PGs previously defined could be summarized as follows: all the strains ( $\mathrm{N}=77$ except one) classified in PG \#301B, C and $\mathrm{D}$ were isolated from environmental samples $(62.2 \%$ 
Table 1 Distribution of $C$. jejuni gyrA alleles by source and conserved nucleotide

\begin{tabular}{|c|c|c|c|c|c|c|c|c|c|c|c|c|c|c|}
\hline \multirow{2}{*}{$\begin{array}{l}\text { Peptide } \\
\text { group }\end{array}$} & \multirow{2}{*}{$\begin{array}{l}\text { Allele } \\
\text { no.* }\end{array}$} & \multicolumn{9}{|c|}{ Nucleotide position } & \multicolumn{3}{|c|}{ Distribution by source } & \multirow{2}{*}{$\begin{array}{l}\text { No. of } \\
\text { ST }\end{array}$} \\
\hline & & 64 & 111 & 210 & 257 & 276 & 324 & 408 & 438 & 486 & SW & DM & $P$ & \\
\hline & 1 & $A$ & $G$ & $C$ & $C$ & G & $A$ & $G$ & C & $A$ & 26 & 27 & 22 & 26 \\
\hline & 4 & . & . & . & . & . & . & . & & . & 2 & 14 & 6 & 6 \\
\hline & 5 & . & . & . & . & . & . & . & & . & 3 & 12 & 10 & 11 \\
\hline & 7 & . & . & . & . & . & . & . & & . & 45 & 8 & 16 & 11 \\
\hline & 11 & & & . & & & & A & . & & 26 & 10 & & 22 \\
\hline & 12 & . & . & . & . & . & . & . & & . & & & 1 & 1 \\
\hline & 13 & . & . & . & . & . & . & . & . & . & 3 & & 4 & 5 \\
\hline & 16 & . & . & . & . & . & . & . & & . & & & 4 & 2 \\
\hline & 18 & & & . & & & & & . & & & & 1 & 1 \\
\hline & 19 & . & . & & . & . & . & . & & . & 6 & & & 1 \\
\hline & 31 & . & . & . & . & & . & . & . & . & 22 & 1 & & 11 \\
\hline \multirow[t]{15}{*}{1} & 36 & & . & . & & & & . & . & . & 5 & & & 5 \\
\hline & 39 & . & . & . & . & . & . & $A$ & & . & 1 & & & 1 \\
\hline & 40 & & . & . & & & & $A$ & . & . & 13 & & & 8 \\
\hline & 41 & . & . & . & . & . & . & $A$ & & . & 3 & & & 3 \\
\hline & 56 & . & . & . & . & & . & $A$ & . & . & 3 & & & 2 \\
\hline & 66 & . & . & . & . & . & . & A & & . & 1 & & & 1 \\
\hline & 73 & & & . & & & & & . & & 1 & & & 1 \\
\hline & 74 & . & . & . & . & . & . & . & & . & 1 & & & 1 \\
\hline & 75 & . & . & $\mathrm{T}$ & . & . & . & . & & . & 1 & & & 1 \\
\hline & 76 & . & . & . & . & . & . & . & & . & 2 & & & 1 \\
\hline & 79 & . & . & . & . & . & . & A & & . & 1 & & & 1 \\
\hline & 80 & . & . & & . & . & . & . & & . & 1 & & & 1 \\
\hline & 2 & . & . & & $T$ & . & . & . & & . & & & 3 & 3 \\
\hline & 3 & & & . & $\mathrm{T}$ & & & & . & & 9 & 3 & 6 & 9 \\
\hline & 8 & . & . & . & $\mathrm{T}$ & . & . & . & & . & 14 & 17 & 13 & 14 \\
\hline \multirow[t]{4}{*}{2} & 15 & . & . & . & $\mathrm{T}$ & . & . & . & & . & & & 2 & 2 \\
\hline & 17 & . & . & . & $\mathrm{T}$ & . & . & . & & . & & & 2 & 2 \\
\hline & 30 & & & . & $\mathrm{T}$ & & & & . & & 3 & & 1 & 4 \\
\hline & 44 & . & . & & $\mathrm{T}$ & . & . & . & & . & & & 2 & 2 \\
\hline \multirow[t]{2}{*}{3} & 6 & G & . & . & . & . & . & . & . & . & & & 1 & 1 \\
\hline & 9 & G & . & & $T$ & . & . & . & & . & 2 & 2 & 20 & 11 \\
\hline \multirow[t]{3}{*}{4} & 53 & $\mathrm{G}$ & . & . & $\mathrm{T}$ & . & . & . & & . & 1 & & & 1 \\
\hline & 78 & $G$ & . & . & $\mathrm{T}$ & & . & . & . & . & & & 1 & 1 \\
\hline & 10 & G & . & & . & . & . & . & . & . & 7 & 4 & 6 & 10 \\
\hline \multirow[t]{2}{*}{5} & 23 & $G$ & . & . & . & & . & . & . & . & & & 1 & 1 \\
\hline & 27 & $\mathrm{G}$ & . & . & . & . & . & . & . & & 1 & & & 1 \\
\hline 6 & 14 & . & . & . & . & . & . & . & . & . & & & 1 & 1 \\
\hline 8 & 24 & $G$ &. & . & $T$ &. &. &. & . & . & & 1 & 1 & 2 \\
\hline \multirow[t]{2}{*}{14} & 54 & . & A & $\mathrm{T}$ & . & A & $\mathrm{G}$ & A & $\mathrm{T}$ & G & 1 & & & 1 \\
\hline & 55 & . & A & $\mathrm{T}$ & . & A & $\mathrm{G}$ & A & $\mathrm{T}$ & $\mathrm{G}$ & 2 & & & 1 \\
\hline 301 & 301 & . & $T$ & $\mathrm{~T}$ & . & A & . & & $A$ & & & & 1 & 1 \\
\hline
\end{tabular}

*Nucleotide allele number, ${ }^{* *} \mathrm{SW}=$ Surface water, $\mathrm{DM}=$ Domesticated Mammals, $\mathrm{P}=$ Poultry. 
Table 2 Distribution of $C$. coli gyrA alleles by source and conserved nucleotide

\begin{tabular}{|c|c|c|c|c|c|c|c|c|c|c|c|c|c|c|c|c|c|c|c|c|c|c|c|c|c|}
\hline \multirow{2}{*}{$\begin{array}{l}\text { Peptide } \\
\text { group* }\end{array}$} & \multirow{2}{*}{$\begin{array}{l}\text { Allele } \\
\text { no. }\end{array}$} & \multicolumn{20}{|c|}{ Nucleotide position } & \multicolumn{3}{|c|}{$\begin{array}{l}\text { Distribution } \\
\text { by source*** }\end{array}$} & \multirow{2}{*}{$\begin{array}{l}\text { No. of } \\
\text { ST }\end{array}$} \\
\hline & & 21 & 69 & 78 & 81 & 90 & 144 & 177 & 180 & 195 & 257 & 267 & 273 & 276 & 279 & 300 & 414 & 417 & 435 & 477 & 495 & sW & DM & $\mathbf{P}$ & \\
\hline \multirow{7}{*}{$301 \mathrm{~A}$} & 301 & A & T & T & $T$ & C & $C$ & $C$ & A & A & $C$ & $C$ & $C$ & A & A & $\mathrm{T}$ & A & $C$ & G & $C$ & G & 1 & 2 & 9 & 11 \\
\hline & 308 & 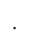 & . & . & & . & . & & . & . & . & . & & . & . & . & . & & . & . & . & 4 & 2 & 14 & 10 \\
\hline & 309 & & . & . & & . & . & & . & . & . & . & & . & . & . & . & & . & . & . & 2 & 11 & 1 & 8 \\
\hline & 312 & . & . & & & . & . & & . & . & & . & & . & . & . & . & & . & . & . & 1 & 1 & 2 & 4 \\
\hline & 316 & & & & . & & . & . & & & & & . & & & & & . & & . & & 4 & 10 & 10 & 18 \\
\hline & 321 & . & . & . & & . & . & & . & . & . & . & & . & . & . & . & & . & . & . & & 2 & & 1 \\
\hline & 318 & . & . & . & & . & . & & . & . & & . & & . & & . & . & & . & & . & 5 & 5 & 5 & 8 \\
\hline \multirow{9}{*}{$301 \mathrm{~B}$} & 323 & . & . & . & . & . & . & G & . & . & . & $T$ & . & G & . & A & G & $\mathrm{T}$ & . & $\mathrm{T}$ & . & 16 & & & 10 \\
\hline & 324 & . & . & . & & . & . & G & G & . & . & T & & G & . & A & G & $\mathrm{T}$ & . & $\mathrm{T}$ & . & 1 & & & 1 \\
\hline & 325 & . & . & & . & . & . & G & . & & & T & . & G & & A & G & $\mathrm{T}$ & . & $\mathrm{T}$ & . & 13 & & & 10 \\
\hline & 327 & . & . & & & & . & G & . & & & T & & G & & A & G & $\mathrm{T}$ & . & $T$ & . & 6 & & & 3 \\
\hline & 334 & . & . & . & & . & . & G & . & . & . & T & & G & . & A & G & $\mathrm{T}$ & . & $\mathrm{T}$ & . & 2 & & & 2 \\
\hline & 342 & . & . & . & & . & . & G & . & . & . & $\mathrm{T}$ & & G & . & A & G & $\mathrm{T}$ & . & $\mathrm{T}$ & . & 2 & & & 1 \\
\hline & 346 & . & . & & . & . & . & G & . & & & $\mathrm{T}$ & & G & & A & G & $\mathrm{T}$ & . & $\mathrm{T}$ & . & 2 & & & 2 \\
\hline & 349 & . & . & & . & & . & $\mathrm{G}$ & . & & & $\mathrm{T}$ & . & G & & A & $\mathrm{G}$ & $\mathrm{T}$ & . & $\mathrm{T}$ & . & 1 & & & 1 \\
\hline & 350 & . & . & . & . & . & . & G & . & . & . & $T$ & . & G & . & A & G & $T$ & . & . & . & 1 & & & 1 \\
\hline \multirow{8}{*}{$301 \mathrm{C}$} & 314 & G & C & C & C & $\mathrm{T}$ & $\mathrm{T}$ & & G & G & . & $T$ & $T$ & G & G & $A$ & G & $T$ & A & $T$ & A & 1 & & 1 & 1 \\
\hline & 329 & G & C & C & $C$ & $\mathrm{~T}$ & $\mathrm{~T}$ & & G & G & . & $\mathrm{T}$ & $T$ & G & G & A & G & $\mathrm{T}$ & A & $\mathrm{T}$ & A & 1 & & & 1 \\
\hline & 330 & $\mathrm{G}$ & C & $C$ & $C$ & $\mathrm{~T}$ & $\mathrm{~T}$ & . & G & G & & $\mathrm{T}$ & $T$ & $\mathrm{G}$ & $\mathrm{G}$ & $A$ & $\mathrm{G}$ & $\mathrm{T}$ & A & $\mathrm{T}$ & A & 2 & & & 2 \\
\hline & 331 & G & C & $C$ & $C$ & $\mathrm{~T}$ & $T$ & & G & G & . & $\mathrm{T}$ & $\mathrm{T}$ & G & G & A & G & $\mathrm{T}$ & A & $\mathrm{T}$ & A & 1 & & & 1 \\
\hline & 336 & G & C & C & $C$ & $\mathrm{~T}$ & $T$ & & G & G & & $\mathrm{T}$ & $\mathrm{T}$ & G & G & A & G & $\mathrm{T}$ & A & $\mathrm{T}$ & A & 3 & & & 3 \\
\hline & 343 & G & C & $C$ & $C$ & $\mathrm{~T}$ & $\mathrm{~T}$ & & G & G & . & $\mathrm{T}$ & $\mathrm{T}$ & G & G & A & G & $\mathrm{T}$ & A & $\mathrm{T}$ & A & 1 & & & 1 \\
\hline & 345 & G & C & C & $C$ & $\mathrm{~T}$ & $T$ & & G & $G$ & . & $\mathrm{T}$ & $T$ & G & $\mathrm{G}$ & A & G & $\mathrm{T}$ & A & $\mathrm{T}$ & A & 1 & & & 1 \\
\hline & 348 & G & C & C & $C$ & $T$ & $\mathrm{~T}$ & . & G & G & & $T$ & $T$ & G & G & A & G & $\mathrm{T}$ & A & $\mathrm{T}$ & A & 1 & & & 1 \\
\hline \multirow{5}{*}{$301 \mathrm{D}$} & 320 & . & & & . & & T & . & & & & . & . & . & & & . & . & . & . & . & 1 & & & 1 \\
\hline & 322 & . & . & . & & . & . & & . & . & . & . & & . & . & . & . & & . & $\mathrm{T}$ & . & 9 & & & 4 \\
\hline & 332 & . & . & . & & . & $\mathrm{T}$ & G & . & . & . & $\mathrm{T}$ & & . & . & . & . & & A & . & . & 7 & & & 1 \\
\hline & 335 & . & . & & & . & . & & . & & & . & & . & . & . & . & . & A & . & . & 4 & & & 3 \\
\hline & 337 & . & & & . & $T$ & . & . & & & & . & . & . & & & & . & & . & . & 1 & & & 1 \\
\hline \multirow{10}{*}{302} & 302 & & . & . & & . & . & & . & . & $\mathrm{T}$ & - & . & . & . & . & . & . & . & . & . & 6 & 5 & 6 & 11 \\
\hline & 303 & & . & . & & . & . & & . & . & $\mathrm{T}$ & & & . & . & . & . & & . & . & . & & & 1 & 1 \\
\hline & 304 & & . & . & & . & . & & . & . & T & . & & . & . & . & . & & . & . & . & 2 & & 9 & 6 \\
\hline & 305 & & & & . & & & . & & & $\mathrm{T}$ & & . & & & & & . & & & & 8 & & 21 & 15 \\
\hline & 306 & . & . & & . & . & . & . & . & & $\mathrm{T}$ & . & . & . & & . & . & . & . & . & . & 6 & 1 & 33 & 23 \\
\hline & 310 & & . & & . & . & . & & . & & $\mathrm{T}$ & . & & . & & . & . & & . & . & . & 1 & & 3 & 1 \\
\hline & 311 & & . & . & & . & . & & . & . & $\mathrm{T}$ & & & & . & . & . & & . & . & & 4 & 5 & 1 & 5 \\
\hline & 307 & & . & . & & . & . & & . & . & $\mathrm{T}$ & & & & . & . & . & & & . & & 2 & 2 & 8 & 11 \\
\hline & 313 & & . & & . & . & . & . & . & & $\mathrm{T}$ & . & & . & & . & . & . & . & . & . & & & 1 & 1 \\
\hline & 319 & . & . & & . & & . & . & . & & $\mathrm{T}$ & . & & . & & . & . & & . & . & . & & & 1 & 1 \\
\hline 1 & 7 & & $\cdot$ & $C$ & . & $T$ & $\mathrm{~T}$ & G & 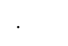 & $\mathrm{T}$ & . & $\mathrm{T}$ & $\mathrm{T}$ & G & $\mathrm{T}$ & . & . & A & & $\mathrm{T}$ & & & & 1 & 1 \\
\hline 2 & 8 & & . & $C$ & & $\mathrm{~T}$ & $\mathrm{~T}$ & $\mathrm{G}$ & & $\mathrm{T}$ & $\mathrm{T}$ & $\mathrm{T}$ & $\mathrm{T}$ & $G$ & $\mathrm{~T}$ & . & . & $A$ & & $\mathrm{~T}$ & & & & 2 & 2 \\
\hline 4 & 9 & & . & $C$ & & $\mathrm{~T}$ & $T$ & $\mathrm{G}$ & . & $\mathrm{T}$ & $\mathrm{T}$ & $\mathrm{T}$ & $\mathrm{T}$ & $G$ & $\mathrm{~T}$ & . & . & $A$ & . & $\mathrm{T}$ & . & & & 3 & 3 \\
\hline 5 & 23 & & & C & . & $\mathrm{T}$ & $\mathrm{T}$ & $\mathrm{G}$ & & $\mathrm{T}$ & & $\mathrm{T}$ & $\mathrm{T}$ & $G$ & $\mathrm{~T}$ & & & $A$ & & $\mathrm{~T}$ & & & & 1 & 1 \\
\hline
\end{tabular}

*Peptide group \#301 is subdivided in 4 parts (A, B, C and D) according to synonymous mutations. * ${ }^{*} \mathrm{SW}=$ Surface water, DM = Domesticated Mammals, $\mathrm{P}=$ Poultry. 

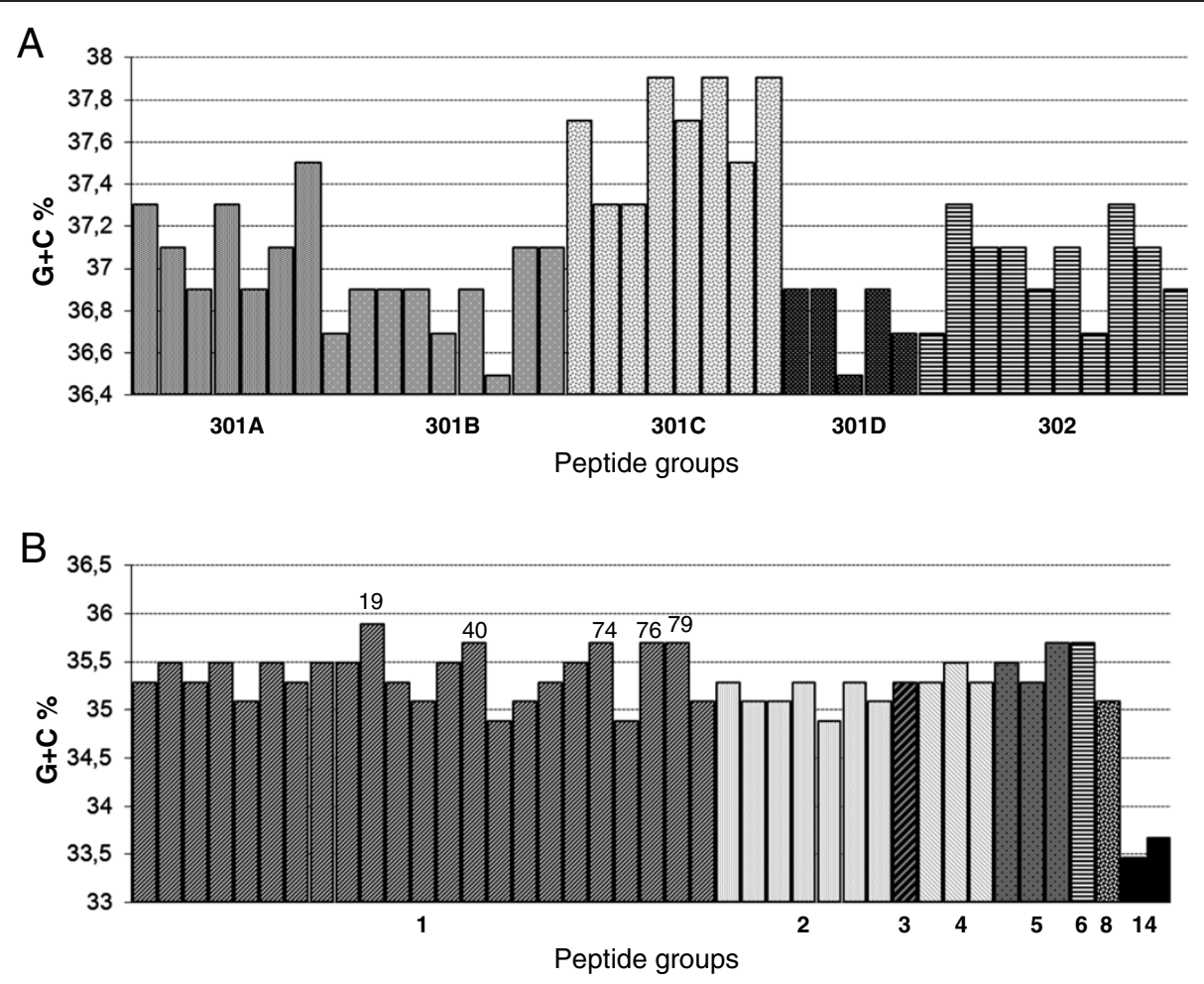

Figure 2 Percentage of GC contents in nucleotide sequences of gyrA alleles arranged by peptide groups. (A) C. coli (B) C. jejuni. Numbers of nucleotide alleles are displayed above the bars for values $>35.5 \%$ in PG\#1.

of the SW collection); poultry strains predominate in PG \#302 ( $\mathrm{N}=84$ i.e. $63.1 \%$ of the $\mathrm{P}$ collection), while all quinolone-sensitive mammal strains were assigned to PG \#301A ( $\mathrm{N}=33$ i.e. $71.7 \%$ of the DM collection). The seven strains harboring a "C. jejuni-like allele" all originate from poultry (Table 2).

\section{Genotype diversity within the $C$. jejuni collection}

All the strains from this study were further characterized by MLST. For the C. jejuni isolates, a total of 170 different STs were identified. Combining MLST with gyrA yielded 191 distinct genotypes. The Simpson's Index of Diversity (SID) was 0.911 (95\% confidence intervals (CI) 0.899-0.923) for gyrA alleles only, 0.979 (95\% CI 0.9740.984) for MLST only and 0.984 (95\% CI 0.979-0.988) for the combination of MLST and $g y r A$. The indexes of association $\mathrm{I}_{\mathrm{A}}$ calculated for each source using a single representative of each genotype, appeared low and fairly similar, suggesting that each of these populations was highly diverse by recombining to some degree: 0.22 (SW), 0.28 (DM) and 0.19 (P). Population differentiation estimated by the $F_{\mathrm{ST}}$ values was highest between SW and DM (0.07787, $P<0.00001)$, followed by DM and $P$ $(0.04074, P<0.00001)$ and lowest for SW and P $(0.03476$, $P<0.00001)$. Nearly half of the strains from the DM set (43.4\%), $18.9 \%$ of the SW set and $23.2 \%$ of the P set had genotypes identified in all three sources (Figure 3A). In the same way, $60.2 \%, 22.2 \%$ and $52.8 \%$ of the strains had genotypes specific to SW, DM and P origins, respectively. Finally, $14.6 \%$ and $6.3 \%$ of the environmental (SW) collection had genotypes common to DM and P sets, respectively. Genotypes not recovered from SW and common to both animal sets represented $15.1 \%$ and $10.4 \%$ of the DM and $\mathrm{P}$ collections, respectively.

\section{Genotype diversity within the $C$. coli collection}

Among the C. coli isolates, a total of 146 STs were identified and yielded 194 distinct genotypes when combined with the gyrA locus. The SID value for the combined methods was of 0.994 (0.992 - 0.996) versus 0.987 (0.984 $0.991)$ for MLST alone or 0.945 (0.936 - 0.953) for the gyrA data alone. The $\mathrm{I}_{\mathrm{A}}$ determined from the SW collection had a value similar to those previously calculated from the $C$. jejuni sets $(0.26)$. In contrast, the $\mathrm{I}_{\mathrm{A}}$ values from each of the animal population displayed a trend closer to zero indicating a random association between alleles of the 8 loci (i.e. in proximity to linkage equilibrium) by freely recombining $\left(\mathrm{I}_{\mathrm{A}}\right.$ for $\mathrm{DM}=0.03$ and $\mathrm{I}_{\mathrm{A}}$ for $\mathrm{P}=$ $0.05)$. The population pairwise $F_{\mathrm{STs}}$ approach generated 3 similar values for each pair combination: SW/DM (0.16295, $P<0.00001)$; SW/P $(0.16455, P<0.00001)$ and $\mathrm{DM} / \mathrm{P}$ (0.15848, $P<0.00001)$. None of the genotypes was common to all three collections of strains as shown in Figure 3B. However, $87.8 \%, 87 \%$ and $76 \%$ of the strains had genotypes 
A

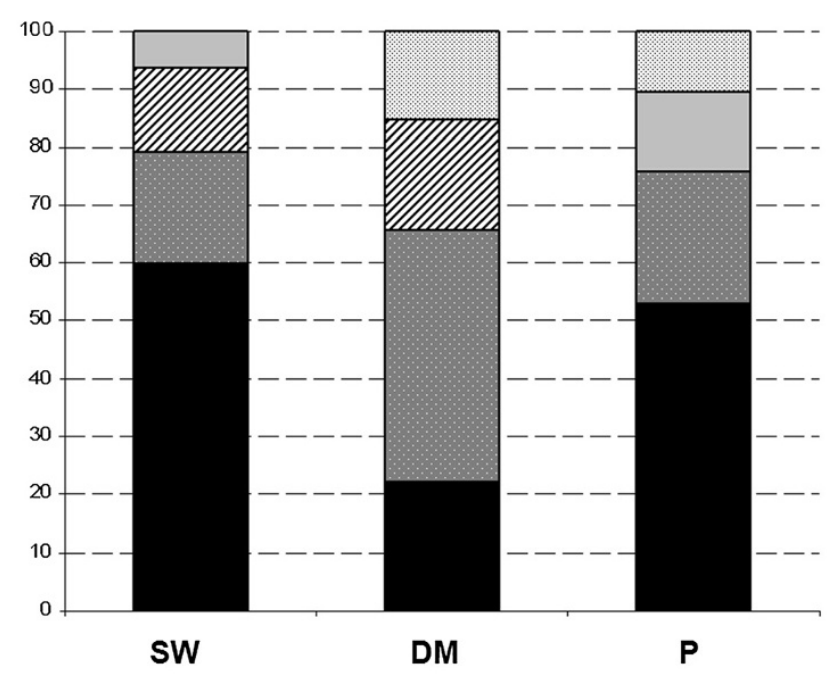

B

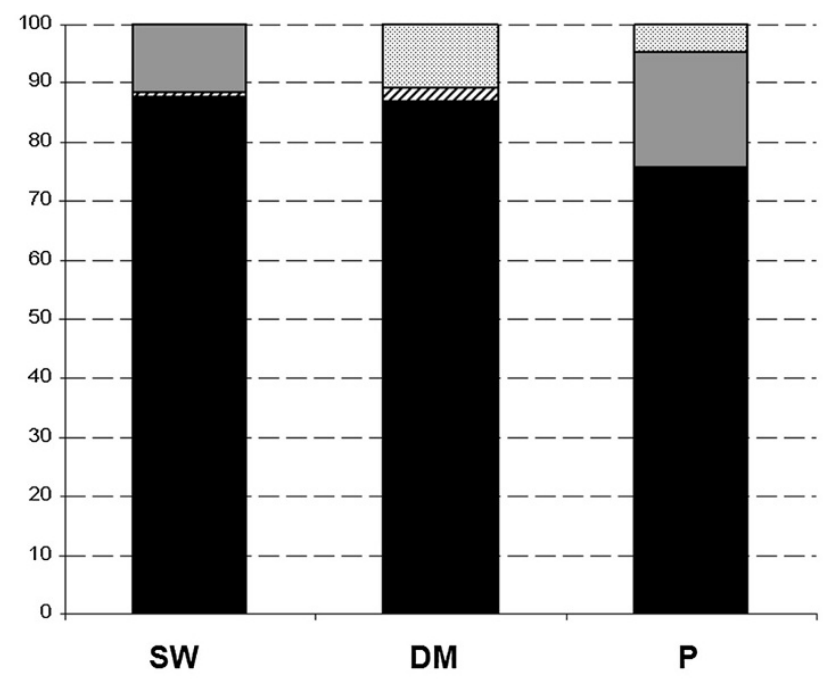

Specific to one source

Surface waters/Poultry

Domestic Mammals/Poultry

Surface waters/Domestic Mammals

\section{Domestic Mammals/Poultry/Surface waters}

Figure 3 Distribution of genotypes (ST + gyrA) by source. (A) C. jejuni collection, (B) C. coli collection. SW = Surface waters, DM = Domesticated Mammals, $P=$ Poultry.

specific to SW, DM and P sources, respectively. In the environmental collection, $0.8 \%$ and $11.4 \%$ of the strains had genotypes common to DM and P sets, respectively. The genotypes recovered only in both animal sources represented $10.9 \%$ and $4.5 \%$ of the DM and P sets, respectively.

\section{Quinolone resistant isolates as defined by the C257T} mutation

Overall, $43.4 \%$ and $17.4 \%$ of $C$. coli and C. jejuni, respectively, were classified as resistant to quinolones according to the C257T mutation (i.e. the peptide shift
Thr86Ile). Quinolone resistance was significantly higher in isolates of poultry origin $(P<0.001)$ for both $C$. coli (67.9\%) and C. jejuni (38.7\%). By comparison, $22.7 \%$ and $16.7 \%$ of the isolates (including both species) originating from the domestic mammals and surface waters, respectively, were quinolone-resistant.

\section{Discussion}

Sequencing of gyrA indicated that this locus was informative in several different ways for characterizing Campylobacter isolates. First, the alleles of the 496 nucleotide 
fragments were suitably different in sequence identity between C. jejuni and C. coli to be assigned to one or the other of these species. The distribution of these alleles confirmed that recombination events between species occur rather infrequently and in an asymmetric gene flow [33]: one $C$. jejuni had a typical $C$. coli allele whereas $4 C$. coli had a typical $C$. jejuni allele. Two other studies using PCR and sequencing data targeting gyrA also identified a $C$. jejuni segment within a $C$. coli isolate $[34,35]$, supporting previous findings that gene flow is rather unidirectional from C. jejuni to C. coli $[33,36]$.

Sequencing of gyrA revealed a similar population structure as that obtained by MLST or rMLST (Ribosomal Multilocus Sequence Typing, [37]). In particular, the phylogenetic analysis clearly organized $C$. coli into 3 distinct clades as previously described by Sheppard et al. [33,36] (Figure 1). Furthermore, peptide groups 301A and 302 in our study (Table 2) contain alleles commonly found in domestic animals, and they correspond to the agricultural $C$. coli lineage of the evolutionary scenario proposed by Sheppard et al. [38]. In addition, peptide groups $301 \mathrm{~B}$ and $301 \mathrm{C}$ (Table 2) match with the clades 2 and 3 observed by Sheppard et al. [38] including only alleles recovered from environmental isolates, i.e. from surface waters in our study. In contrast to C. jejuni, the C. coli assigned alleles are predominated by synonymous mutations. As a result, the peptide group $301 \mathrm{C}$ is characterized by alleles with a higher GC content (Figure 2A) generated by nucleotide changes only located in the third positions of codons. This trend was also reflected in genotypes linked to this peptide group $301 \mathrm{C}$ i.e. by compiling GC content from the internal fragments of the 7 MLST housekeeping genes with the gyrA alleles (a total of 3,805 bp in length, see Additional file 1). This kind of GC rich version of genes, independent of adaptive codon usage was significantly associated with effects on bacterial fitness, which could be explained by higher stability of mRNAs [39]. The study of Foerstner et al. [40] linked the genomic GC pattern of bacterial populations to environmental factors like ultraviolet irradiation as an example. Thus, the difference in synonymous GC contents found in the gyrA alleles from the peptide groups $301 \mathrm{~B}$ and $301 \mathrm{C}$, suggests that these lineages originated from two distinct but not yet identified ecological niches. By using concatenated nucleotide sequences from MLST data, isolates from our gyrA peptide group 301B would be classified in the clade 2 from the study of Colles et al. [41] (see Additional file 2) including the majority of the STs identified from wild Mallard ducks. Among our collection of surface water isolates, we similarly observed three clades: one associated with domestic animals and the other two of wildlife origin, one of which potentially linked to waterfowl. Nevertheless, with a more discriminative approach based on genotypes defined by combining the 7 housekeeping genes from MLST with the gyrA, the populations of $C$. coli displayed a high specificity in their distribution by sources (Figure 3). None of the 194 genotypes identified was found in all three collections (SW, DM and P) and $F_{\mathrm{STs}}$ values calculated by pair comparisons were about 4 times higher than those computed from $C$. jejuni pairs. The fact that domesticated mammal isolates were poorly represented in our environmental samples could have resulted from a temporal and geographic sampling bias. Half of the collection was mainly isolated in 2006 [3] and the other half was collected from distant geographic locations. As to the isolates originating from poultry, it must be emphasized here that domestic production of broilers is negligible and there is no poultry hatchery in the country. Thus, direct contamination of environmental waters by local poultry farms is largely restricted.

Regarding the C. jejuni gyrA sequences, two lineages were clearly distinguished (Figure 1). One branch is represented by the peptide group \#14, encoded by the alleles \#54 and \#55 recovered from surface waters isolates only. These nucleotide sequences are again mainly differentiated by their GC content, but this time, below the mean of each of the other groups (Figure 2). The two STs associated with these strains are newly described (ST 5841 and ST 6171) and correspond to variants of $a$ C. jejuni clone associated with bank voles [42]. Interestingly, these strains also displayed atypical profiles with the duplex-real time PCR implemented in this study for identifying isolates at the species level. An extra PCR was needed to confirm the presence of the hipO gene (see the Methods section). In summary, this phylogenetic lineage originated from a wildlife source, whereas the other one is composed of $g y r A$ alleles mainly shared by domesticated mammals. However, the peptide group \#1 from the main branch which is encoded by the largest number of alleles $(\mathrm{N}=23)$, could be subdivided into two sets of sub-clusters: one set harboring strains isolated from domestic mammals $(\mathrm{N}=9)$ and the other set being highly specific to environmental samples $(\mathrm{N}=14)$. From this last set, five sequences (\#19, 40, 74, 76 and 79) display a slightly higher GC content (Figure $2 \mathrm{~B}$ ) as a potential "trace signature" of different ecological niches. In addition, within this same peptide group \#1, the nucleotide alleles with the synonymous substitution G408A (\#11, 39, 40, 41, 56, 66 and 79) were never recovered from poultry strains. This change is also present in alleles from peptide group \#14 previously discussed and linked to small mammals [42]. The most obvious host signature established in our study is the non-synonymous substitution A64G corresponding to the change Ser22Gly in the amino acid sequence. This point mutation was previously observed by Ge et al. [43] in a study on antimicrobial resistance of strains isolated from poultry meat in 
which $76.2 \%$ ciprofloxacin-resistant $C$. jejuni harbored this particular substitution in their gyrA sequence $(\mathrm{N}=42)$. Jesse et al. [44] also noticed this mutation in isolates from chicken and turkeys and suggested that it does not contribute to quinolone resistance but may be indicative of gyrA alleles predominantly found in poultry. Our results confirm this finding: 11 isolates with the Ser22Gly but without the Thr86Ile substitution were classified as susceptible to quinolones according to the cut off values recommended by the European commission [45] (see Additional file 3). Also, peptide groups \#3, 4, 5 and 8 with this particular change on codon 22 , are significantly associated with poultry source $(P=0.001)$. This host signature could be used as a specific molecular marker of domestic birds.

Our study also found that quinolone resistance was higher in isolates originating from poultry than from other sources. Recently, Han et al. [46] demonstrated that this particular mutation generates a fitness advantage for Campylobacter in chicken through a reduced supercoiling activity of the GyrA enzyme. As DNA supercoiling is directly involved in gene expression, their findings suggested that the altered function of the enzyme modulates the fitness of resistant strains whose prevalence persists in poultry production even in the absence of fluoroquinolone use. The European report on antimicrobial resistance in zoonotic bacteria [12] reported very high fluoroquinolone resistance levels in Campylobacter isolated from broilers (76\%) and broiler meat (58\%). Our results concur with the report in that resistance levels vary substantially in different hosts.

\section{Conclusion}

The interest of the sequence-based method described herein targeting the gyrase subunit A lies not only in providing information on quinolone resistance but also on strain origin. As the gyrase is an essential gene for bacterial viability and also plays a role in gene expression, some patterns in sequences appear to be informative as potential host signature, predictive of particular ecological niches. All the sequences of alleles defined here are freely accessible on the website of the Campylobacter MLST website (http://pubmlst.org/campylobacter/) developed by Keith Jolley and sited at the University of Oxford [47]. We believe that this tool could be useful for basic surveillance of campylobacteriosis in two ways. For long-term surveillance, it could be combined with MLST data for increased discrimination power, and would help in identifying source attribution of ST complexes shared by more than one sample population: ST21, ST45 and ST48 complexes for example [48]. For short term surveillance i.e. detection of temporal clusters of human cases, it could provide some indication on the potential infection source involved when combined with porA or flaA typing [8].

\section{Additional files}

\begin{abstract}
Additional file 1: GC contents using concatenated nucleotide sequence: 7 housekeeping genes from MLST with gyrA alleles (3805 bp). Results from the 187 genotypes are classified according gyrA peptide groups. Average in GC\% for each group are shown.
\end{abstract}

Additional file 2: Neighbour-joining radial distance phylogenetic tree constructed with concatenated nucleotide sequences from STs identified from this study and from Colles et al. [41] on wild and domesticated ducks.

Additional file 3: MICs recorded for C. jejuni isolates with Ser22Gly but without the Thr86lle substitution. Interpretative thresholds for resistance $(R):$ CIP_R $>0.5$ and $N A L \_R>16$.

\section{Competing interests}

The authors declare that they have no competing interests.

\section{Authors' contributions}

CR conceived the typing method, coordinated the study, conducted data analysis and drafted the manuscript; SC conducted laboratory work associated with sequencing and participated in data analysis of the Campylobacter coli species; CP conceived the methodology for recovering isolates from environmental/animals samples, performed environmental sampling and revised the manuscript; HMC coordinated the sampling strategies for collecting environmental isolates and revised the manuscript; AD performed the statistical analyses; FD developed the PCR assays for identifying isolates at the species level, SL isolated strains from veterinarian samples and food products at retail; JM initiated and managed the genotyping platforms for the national surveillance system, discussed analyses, interpretation and revised the manuscript critically. All authors read and approved the final manuscript.

\section{Acknowledgements}

This work is a part of the HypoCamp project funded by the National Research Fund of Luxembourg (contract number C09/BM/09). We are grateful to Dr. Keith Jolley and Dr. Alison Cody for publishing our gyrA data on the freely accessible website of the Campylobacter Multi Locus Sequence Typing website: http://pubmlst.org/campylobacter/. We thank Dr. Martine Denis, Dr. Katell Rivoal (ANSES, Ploufragan, France) as well as Dr. Nadine Botteldoorn and Dr. Sarah Denayer (WIV-ISP, Brussels, Belgium) for providing Campylobacter coli strains of porcine origin. We thank Dr. Christophe Olinger for assistance in the construction of the phylogenetic tree and Dr. Monique Perrin for antimicrobial susceptibility data. Delphine Collard and Cécile Walczak are acknowledged for their environmental sampling efforts and experimental assistance. We thank Dr. Nathalie Welschbillig from the National task force "National Priority Campylobacter" for her participation together with the official veterinarians of the State Veterinary Services and veterinarian practitioners in collecting isolates from veterinarian samples.

\section{Author details}

${ }^{1}$ National Health Laboratory, Surveillance and Epidemiology of Infectious Diseases, 1 rue Louis Rech, Dudelange L-3555, Luxembourg. ${ }^{2}$ Centre de Recherche Public Santé, 1A-B rue Thomas Edison, Strassen L-1445, Luxembourg. ${ }^{3}$ National Health Laboratory, Bacteriology- ParasitologyMycology, 1 rue Louis Rech, Dudelange L-3555, Luxembourg. ${ }^{4}$ Département Environnement et Agro-Biotechnologies, Centre de Recherche Public Gabriel Lippmann, 41 rue du Brill, Belvaux L-4422, Luxembourg. ${ }^{5}$ Veterinary Medecine Laboratory, 54, av. Gast Diderich, Luxembourg L-1420, Luxembourg.

Received: 31 March 2014 Accepted: 18 July 2014 Published: 28 August 2014

\section{References}

1. EFSA, (European Food Safety Authority), ECDC, (European Centre for Disease Prevention and Control): The European Union Summary Report on Trends and Sources of Zoonoses, Zoonotic Agents and Food-borne Outbreaks in 2011. EFSA J 2013, 11(4):3129. 
2. Sécurité alimentaire/Luxembourg - Rapports d'Activité - OSQCA. [http://www.securite-alimentaire.public.lu/organisme/rapports_activite_ osqca/index.html]

3. Ragimbeau C, Schneider F, Losch S, Even J, Mossong J: Multilocus sequence typing, pulsed-field gel electrophoresis, and fla short variable region typing of clonal complexes of campylobacter jejuni strains of human, bovine, and poultry origins in Luxembourg. Appl Environ Microbiol 2008, 74:7715-7722.

4. Mughini Gras L, Smid JH, Wagenaar JA, De Boer AG, Havelaar AH, Friesema IHM, French NP, Busani L, Van Pelt W: Risk factors for campylobacteriosis of chicken, ruminant, and environmental origin: a combined casecontrol and source attribution analysis. PLoS One 2012, 7:e42599.

5. Strachan NJC, Gormley FJ, Rotariu O, Ogden ID, Miller G, Dunn GM, Sheppard SK, Dallas JF, Reid TMS, Howie H, Maiden MCJ, Forbes KJ: Attribution of campylobacter infections in Northeast Scotland to specific sources by use of multilocus sequence typing. J Infect Dis 2009, 199:1205-1208.

6. Wilson DJ, Gabriel E, Leatherbarrow AJH, Cheesbrough J, Gee S, Bolton E, Fox A, Fearnhead P, Hart CA, Diggle PJ: Tracing the source of campylobacteriosis. PLoS Genet 2008, 4.

7. Dingle KE, Colles FM, Ure R, Wagenaar JA, Duim B, Bolton FJ, Fox AJ, Wareing DRA, Maiden MCJ: Molecular characterization of campylobacter jejuni clones: a basis for epidemiologic investigation. Emerg Infect Dis 2002, 8:949-955.

8. Dingle KE, McCarthy ND, Cody AJ, Peto TEA, Maiden MCJ: Extended sequence typing of Campylobacter spp., United Kingdom. Emerg Infect Dis 2008, 14:1620-1622.

9. McCarthy ND, Colles FM, Dingle KE, Bagnall MC, Manning G, Maiden MCJ, Falush D: Host-associated genetic import in Campylobacter jejuni. Emerg Infect Dis 2007, 13:267-272.

10. Maiden MCJ, Bygraves JA, Feil E, Morelli G, Russell JE, Urwin R, Zhang Q, Zhou J, Zurth K, Caugant DA, Feavers IM, Achtman M, Spratt BG: Multilocus sequence typing: a portable approach to the identification of clones within populations of pathogenic microorganisms. Proc Natl Acad Sci U S A 1998, 95:3140-3145.

11. Wieczorek K, Osek J: Antimicrobial resistance mechanisms among campylobacter. Biomed Res Int 2013, 2013:340605.

12. EFSA, (European Food Safety Authority), ECDC, (European Centre for Disease Prevention and Control): The European Union Summary Report on antimicrobial resistance in zoonotic and indicator bacteria from humans, animals and food in 2011. EFSA J 2013, 11:11 [3196].

13. WHO: WHO list of Critically Important Antimicrobials (CIA). [http://www.who.int/foodborne_disease/resistance/cia/en/]

14. European Medicines Agency: Sales of veterinary antimicrobial agents in 25 EU/EEA countries in 2011. 2013.

15. Agents EFSA-WG on DHS for MAR in Z: Harmonised monitoring of antimicrobial resistance in Salmonella and Campylobacter isolates from food animals in the European Union. Clin Microbiol Infect 2008, 14:522-533.

16. Ge B, Wang F, Sjölund-Karlsson M, McDermott PF: Antimicrobial resistance in Campylobacter: susceptibility testing methods and resistance trends. J Microbiol Methods 2013, 95:57-67.

17. Payot S, Bolla J-M, Corcoran D, Fanning S, Mégraud F, Zhang Q: Mechanisms of fluoroquinolone and macrolide resistance in Campylobacter spp. Microbes Infect 2006, 8:1967-1971.

18. Wang Y, Huang WM, Taylor DE: Cloning and nucleotide sequence of the Campylobacter jejuni gyrA gene and characterization of quinolone resistance mutations. Antimicrob Agents Chemother 1993, 37:457-463.

19. Ragimbeau C, Salvat G, Colin P, Ermel G: Development of a multiplex PCR gene fingerprinting method using gyrA and pflA polymorphisms to identify genotypic relatedness within Campylobacter jejuni species. J Appl Microbiol 1998, 85:829-838.

20. Ragimbeau C, Gadisseux L, Penny C, Cauchie H, Devaux A, Mossong J: Evaluation of molecular genetic markers to combine with MLST data for tracing host and transmission routes of Campylobacter jejuni in Luxembourg. In 16th Int Workshop Campylobacter Helicobacter Relat Org. Vancouver: 2011. August 28-September 1:124.

21. LaGier MJ, Joseph LA, Passaretti TV, Musser KA, Cirino NM: A real-time multiplexed PCR assay for rapid detection and differentiation of Campylobacter jejuni and Campylobacter coli. Mol Cell Probes 2004, 18:275-282.

22. Ménard A, Dachet F, Prouzet-Mauleon V, Oleastro M, Mégraud F: Development of a real-time fluorescence resonance energy transfer PCR to identify the main pathogenic Campylobacter spp. Clin Microbiol Infect 2005, 11:281-287.

23. Gorman R, Adley CC: An evaluation of five preservation techniques and conventional freezing temperatures of -20 degrees $C$ and -85 degrees C for long-term preservation of Campylobacter jejuni. Lett Appl Microbio/ 2004, 38:306-310.

24. Campylobacter MLST Home Page. [http://pubmlst.org/campylobacter/]

25. Dingle KE, Colles FM, Wareing DR, Ure R, Fox AJ, Bolton FE, Bootsma HJ, Willems RJ, Urwin R, Maiden MC: Multilocus sequence typing system for Campylobacter jejuni. J Clin Microbiol 2001, 39:14-23.

26. Dingle KE, Colles FM, Falush D, Maiden MCJ: Sequence typing and comparison of population biology of Campylobacter coli and Campylobacter jejuni. J Clin Microbiol 2005, 43:340-347.

27. Jolley KA, Feil EJ, Chan MS, Maiden MC: Sequence type analysis and recombinational tests (START). Bioinformatics 2001, 17:1230-1231.

28. Excoffier L, Laval G, Schneider S: Arlequin (version 3.0): an integrated software package for population genetics data analysis. Evol Bioinform Online 2005, 1:47-50

29. Comparing Partitions Website. [http://darwin.phyloviz.net/Comparing Partitions/index.php?link=Home]

30. Carriço JA, Silva-Costa C, Melo-Cristino J, Pinto FR, De Lencastre H, Almeida JS, Ramirez M: Illustration of a common framework for relating multiple typing methods by application to macrolide-resistant Streptococcus pyogenes. J Clin Microbiol 2006, 44:2524-2532.

31. Hall T: BioEdit: a user-friendly biological sequence alignment editor and analysis program for Windows 95/98/NT. Nucleic Acids Symp Ser 1999, 41:95-98.

32. Tamura K, Peterson D, Peterson N, Stecher G, Nei M, Kumar S: MEGA5: molecular evolutionary genetics analysis using maximum likelihood, evolutionary distance, and maximum parsimony methods. Mol Biol Evol 2011, 28:2731-2739.

33. Sheppard SK, McCarthy ND, Falush D, Maiden MCJ: Convergence of Campylobacter species: implications for bacterial evolution. Science 2008, 320:237-239.

34. Korczak BM, Zurfluh M, Emler S, Kuhn-Oertli J, Kuhnert P: Multiplex strategy for multilocus sequence typing, fla typing, and genetic determination of antimicrobial resistance of Campylobacter jejuni and Campylobacter coli isolates collected in Switzerland. J Clin Microbiol 2009, 47:1996-2007.

35. Said MM, El-Mohamady H, El-Beih FM, Rockabrand DM, Ismail TF, Monteville MR, Ahmed SF, Klena JD, Salama MS: Detection of gyrA mutation among clinical isolates of Campylobacter jejuni isolated in Egypt by MAMA-PCR. J Infect Dev Ctries 2010, 4:546-554.

36. Sheppard SK, Didelot X, Jolley KA, Darling AE, Pascoe B, Meric G, Kelly DJ, Cody A, Colles FM, Strachan NJC, Ogden ID, Forbes K, French NP, Carter P, Miller WG, McCarthy ND, Owen R, Litrup E, Egholm M, Affourtit JP, Bentley SD, Parkhill J, Maiden MCJ, Falush D: Progressive genome-wide introgression in agricultural Campylobacter coli. Mol Ecol 2013, 22:1051-1064.

37. Ribosomal Multilocus Sequence Typing (rMLST) - PubMLST.org. [http://pubmlst.org/rmlst/]

38. Sheppard SK, Dallas JF, Wilson DJ, Strachan NJC, MCCarthy ND, Jolley KA, Colles FM, Rotariu O, Ogden ID, Forbes KJ, Maiden MCJ: Evolution of an agriculture-associated disease causing Campylobacter coli clade: evidence from national surveillance data in Scotland. PLoS One 2010, 5:e15708.

39. Raghavan R, Kelkar YD, Ochman H: A selective force favoring increased $\mathrm{G}+\mathrm{C}$ content in bacterial genes. Proc Natl Acad Sci U S A 2012, 109:14504-14507.

40. Foerstner KU, Von Mering C, Hooper SD, Bork P: Environments shape the nucleotide composition of genomes. EMBO Rep 2005, 6:1208-1213.

41. Colles FM, Ali JS, Sheppard SK, McCarthy ND, Maiden MCJ: Campylobacter populations in wild and domesticated Mallard ducks (Anas platyrhynchos). Environ Microbiol Rep 2011, 3:574-580.

42. Williams NJ, Jones TR, Leatherbarrow HJ, Birtles RJ, Lahuerta-Marin A Bennett M, Winstanley C: Isolation of a novel Campylobacter jejuni clone associated with the bank vole, Myodes glareolus. Appl Environ Microbiol 2010, 76:7318-7321.

43. Ge B, White DG, McDermott PF, Girard W, Zhao S, Hubert S, Meng J: Antimicrobial-resistant Campylobacter species from retail raw meats. Appl Environ Microbiol 2003, 69:3005-3007.

44. Jesse TW, Englen MD, Pittenger-Alley LG, Fedorka-Cray PJ: Two distinct mutations in gyrA lead to ciprofloxacin and nalidixic acid resistance in 
Campylobacter coli and Campylobacter jejuni isolated from chickens and beef cattle. J Appl Microbiol 2006, 100:682-688.

45. EUR-Lex - 32013D0652 - EN - EUR-Lex. [http://eur-lex.europa.eu/legalcontent/EN/TXT/?qid =1404378765237\&uri=CELEX:32013D0652]

46. Han J, Wang Y, Sahin O, Shen Z, Guo B, Shen J, Zhang Q: A

fluoroquinolone resistance associated mutation in gyrA Affects DNA supercoiling in Campylobacter jejuni. Front Cell Infect Microbiol 2012, 2:21.

47. Jolley KA, Maiden MC: BIGSdb: Scalable analysis of bacterial genome variation at the population level. BMC Bioinformatics 2010, 11:595.

48. Sheppard SK, Dallas JF, MacRae M, McCarthy ND, Sproston EL, Gormley FJ, Strachan NJC, Ogden ID, Maiden MCJ, Forbes KJ: Campylobacter genotypes from food animals, environmental sources and clinical disease in Scotland 2005/6. Int J Food Microbiol 2009, 134:96-103.

doi:10.1186/s12866-014-0205-7

Cite this article as: Ragimbeau et al: Investigating the host specificity of Campylobacter jejuni and Campylobacter coli by sequencing gyrase subunit A. BMC Microbiology 2014 14:205.

\section{Submit your next manuscript to BioMed Central and take full advantage of:}

- Convenient online submission

- Thorough peer review

- No space constraints or color figure charges

- Immediate publication on acceptance

- Inclusion in PubMed, CAS, Scopus and Google Scholar

- Research which is freely available for redistribution 